\title{
A Gravid Indonesian Red-tailed Green Ratsnake (Gonyosoma oxycephalum [Boie 1827]) in the Pet Trade
}

\author{
Simon Dieckmann ${ }^{1}$, Gerrut Norval ${ }^{2}$, and Jean-Jay Mao ${ }^{3}$ \\ 1Ji-an Township, Hualien County, 973, Taiwan, R.O.C. (gujonaan@yahoo.de) \\ ${ }^{2}$ Applied Behavioural Ecology \& Ecosystem Research Unit, Department of Environmental Sciences, UNISA, Republic of South Africa (corresponding author: \\ gnorval@gmail.com) \\ ${ }^{3}$ Department of Forestry and Natural Resources, National Ilan University. Ilan, 260, Taiwan, R.O.C. (jjmao@niu.edu.tw)
}

Photographs by the senior author.

$\mathrm{T}$

The Red-tailed Green Ratsnake (Gonyosoma [Elaphe] oxycephalum [Boie 1827]; Fig. 1) occurs in lowland $(<750$ $\mathrm{m}$ asl) primary and secondary forests in parts of Cambodia, India, Indonesia, Laos, Malaysia, Myanmar (= Burma), the Philippine Islands, Singapore, Thailand, and Vietnam (Schulz 1996). In captivity, G. oxycephalum requires tall spacious humid terraria that should be kept fairly warm (25-29 $\left.{ }^{\circ} \mathrm{C}\right)$ (Schulz 1996). These snakes are quite large and exhibit aggressive defensive behaviors (Mattison 1999). In spite of these challenges, these snakes are imported and kept as pets in many parts of the world (Heijnen 1988).

On 29 November 2013, the first author obtained a male and female G. oxycephalum from a pet importer in Taiwan, who stated that the snakes were collected from the wild in Indonesia. The female (Fig. 2), which had a total length of ca. $150 \mathrm{~cm}$, appeared emaciated. On the morning of 30 November 2013, we discovered that she had deposited six eggs during the previous night. The eggs ranged in length and

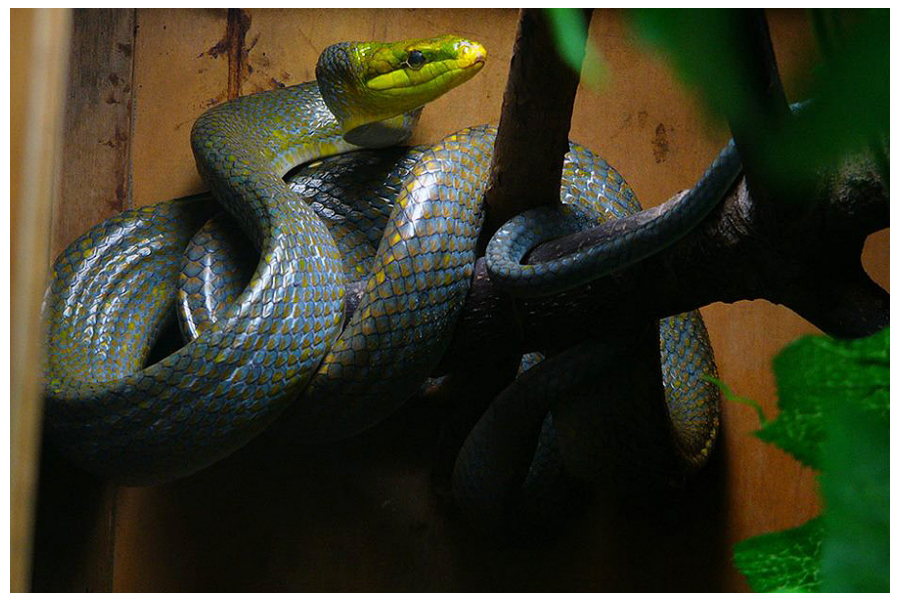

Fig. 1. The Red-tailed Green Ratsnake (Gonyosoma oxycephalum) is primarily an arboreal species.

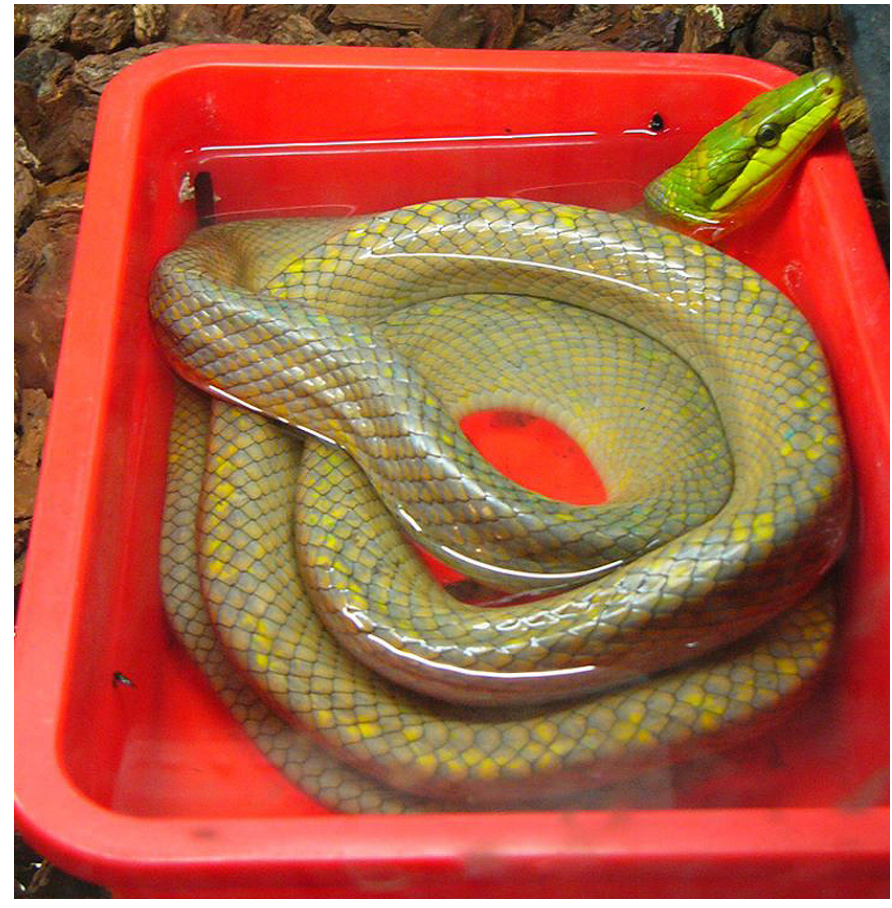

Fig. 2. The Red-tailed Green Ratsnake (Gonyosoma oxycephalum) female described herein, after acclimation to her cage.

width from 60 to $68 \mathrm{~mm}$ (mean $\pm \mathrm{SD}=63.2 \pm 2.9 \mathrm{~mm}$ ) and 23 to $27 \mathrm{~mm}$ (mean $\pm \mathrm{SD}=25.2 \pm 1.7 \mathrm{~mm}$ ), respectively. The eggs were bound together and had a combined weight of 122 g. No attempts were made to separate the eggs, and after the length, width, and weight of the eggs were recorded, they were placed inside an incubator. The daytime temperature in the incubator was ca. $29^{\circ} \mathrm{C}$ and ca. $27^{\circ} \mathrm{C}$ at night. Moisture in the incubator was maintained at $85-95 \%$. The relative clutch mass $(0.35)$ was calculated using the formula: total clutch weight / maternal post-oviposition body weight (Shine 1980). 
The hatchlings started to emerge on 1 March 2014 and the last hatchling emerged from its egg the following day. To avoid injury to the hatchlings, we made no initial attempts to sex them; when they were a few weeks old, we sexed them by cloacal popping and determined that three were males and three were females. The hatchlings resembled the adults in coloration (Figs. $3 \& 4$ ), and no color-based sexual dimorphism was noted. The hatchlings ranged in total lengths (measured with a ruler to the nearest $\mathrm{cm}$ ) and body weights from 39 to 47 $\mathrm{cm}($ mean $\pm \mathrm{SD}=43.8 \pm 2.7 \mathrm{~cm})$ and 19 to $22 \mathrm{~g}($ mean $\pm \mathrm{SD}$ $=20.3 \pm 1.4 \mathrm{~g}$ ), respectively. They were housed independently in small plastic animal cages (length $\mathrm{x}$ width $\mathrm{x}$ height $=45 \times 25$ x $25 \mathrm{~cm}$ ); and each cage was provided with a water bowl and a shelter, and paper towels were used as a substrate.

An understanding of the natural history of a species is essential for successful conservation and management programs (Greene 1994; Bury 2006), and a crucial part of the natural history of any species is its reproductive biology. Although information from animals in captivity should be interpreted with caution, it can be incorporated with data collected from the wild to develop a better understanding of the life history of a species. Clutch sizes of $G$. oxycephalum range from five to 12 eggs (Schulz 1996), and eggs are about 70 $\mathrm{mm}$ in length (Heijnen 1988; Das 2002), so our observations are not exceptional. The incubation period in our study (91 days) is shorter than the 100-120 days reported by Das (2002) and the 122 days reported by Heijnen (1988), but is slightly longer than the 85 days reported by Van Riel (1991). The hatchlings described herein were similar in size and weight to those reported by Heijnen (1988; total length ca. 47-50 cm; weight ca. 15-22 g), Van Riel (1991; total length

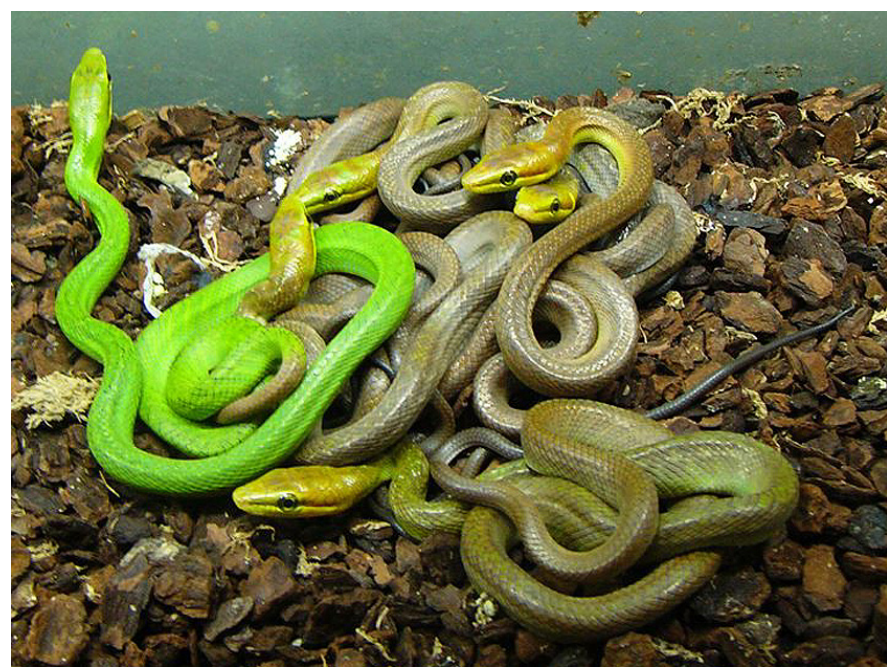

Fig. 3. Red-tailed Green Ratsnake (Gonyosoma oxycephalum) hatchlings described herein ranged in coloration from the typical green coloration of this species to the grayish coloration associated with some snakes from Java.

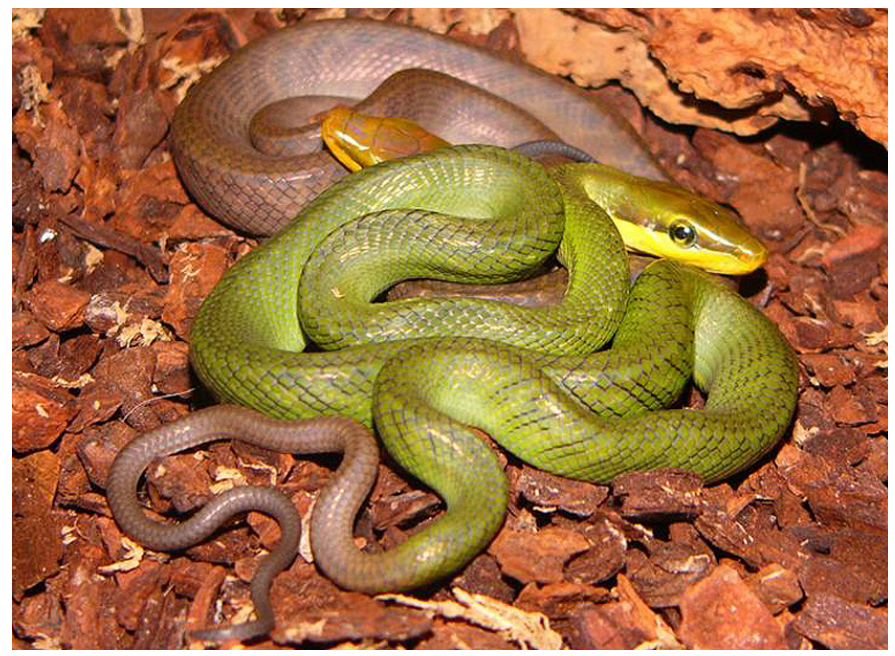

Fig. 4. Two of the Red-tailed Green Ratsnake (Gonyosoma oxycephalum) hatchlings described herein.

ca. $46 \mathrm{~cm}$; ca. $18.5 \mathrm{~g}$ ), and Schulz (1996; total length 40-55 $\mathrm{cm})$. To our knowledge this is the first reported description of a $G$. oxycephalum relative clutch mass, so no comparisons can be made.

The trade in reproductive females, as described herein, should be avoided as far as possible. The loss of reproductive females collected from the wild negatively affects the viability of the population from which they are removed because it not only entails the removal of the female, but also the young that could have been recruited into the population. In addition, the physical demands of reproduction, combined with the stress associated with quarantine, shipment, and acclimation, inevitably reduce the likelihood of survival.

We thus recommend that season and/or size-limit restrictions be implemented for wild-caught reptiles in the pet trade. This would increase the likelihood that animals are collected outside the breeding season or involve only individuals that are not yet sexually mature.

\section{Literature Cited}

Bury, B.R. 2006. Natural history, field ecology, conservation biology and wildlife management: Time to connect the dots. Herpetological Conservation and Biology 1:56-61.

Das, I. 2002. A Photographic Guide to Snakes and Other Reptiles of India. New Holland Publishers Ltd., London, UK.

Greene, H.W. 1994. Systematics and natural history, foundations for understanding and conserving biodiversity. American Zoologist 34:48-56.

Heijnen, G.H. 1988. De verzorging van en de kweek met de spitskopslang (Gonyosoma oxycephala). Lacerta 47:24-29.

Mattison, C. 1999. Snake. Dorling Kindersley Ltd., London.

Schulz, K.D. 1996. A Monograph of the Colubrid Snakes of the Genus Elaphe Fitzinger. Koeltz Scientific Books, Koenigstein, Germany.

Van Riel, C.A.P. 1991. Voortplanting in het terrarium van de Roodstaartslang (Gonyosoma oxycephala). Lacerta 50:39-42. 